Journal of Case Reports 2018;8(2):162-164

\title{
An Unusual Presentation of Prinzmetal Angina
}

\author{
Krunal V Desai, Sandeep Jain, Anoop Prukayastha, Manish Mehta \\ Department of Emergency Medicine, Max Super Speciality Hospital, Saket, New Delhi.
}

\section{Corresponding Author:}

Dr. Krunal V Desai

Email: krunaldesai3991@gmail.com

This is an Open Access article distributed under the terms of the Creative Commons Attribution License (creativecommons.org/ licenses/by/3.0).

Received : March 9, 2018

Accepted : June 19, 2018

Published : June 30, 2018

\begin{abstract}
Background: Atypical presentation of Prinzmetal angina is a challenge to an astute emergency physician. Case Report: A 51 year male, known case of chronic kidney disease presented to Emergency Department (ED) with complaints of intermittent altered mental status since last 6 hours prior to ED arrival. In between patient was neurologically intact. Frequency of these episodes was gradually increasing. On ED evaluation patient was conscious, oriented and hemodynamically stable. Initial electrocardiogram (ECG) and biochemical markers did not show any abnormality. During next episode of altered mental status, ECG showed ST elevation in infero-posterior leads which returned back to normal sinus rhythm within 20 minutes. This was a case of Prinzmetal angina which can be missed easily, if not suspected. Conclusion: Awareness regarding existence of Prinzmetal angina is important to emergency physician.
\end{abstract}

Keywords: Prinzmetal angina, Variant Angina, Vasospastic Angina.

\section{Introduction}

Prinzmetal angina was first described by Myron Prinzmetal in 1959 in American Journal of Medicine. It is rare, representing about two out of 100 cases of angina, and usually occurs in younger patients [1]. Patient who present with this kind of angina is a challenge to an astute emergency physician. These patients may present with nonspecific symptoms and can be easily missed in the absence of awareness amongst emergency physician. We hereby report a case of Prinzmetal angina with atypical symptoms.

\section{Case Report}

A 51 year old male presented to the Emergency Department with complaints of forgetfulness and excessive speech for past 6 hours. He had one episode of fever 2 days ago. He did not report any loss of consciousness, seizure, chest pain or palpitations. Patient was a known hypertensive, endstage renal disease on maintenance hemodialysis and prospective renal allograft recipient.
Electrocardiogram (ECG) and echocardiography done as part of pre-anaesthetic check-up revealed no abnormalities. His last haemodialysis session was one day before presentation. Family history was non-contributory. On initial assessment, his airway, breathing and circulation were not compromised and initial set of vital signs were within normal limits, with full GCS and a blood glucose level of $114 \mathrm{mg} / \mathrm{dL}$. Systemic examination revealed no positive signs. Initial ECG showed normal sinus rhythm [Fig.1].

Biochemical investigations did not reveal any abnormalities. In view of intermittency of the complaints patient was kept under observation in ED on a monitored bed. Four hours later, patient had an episode of profuse sweating and disorientation. A repeat of his baseline vital signs revealed hypotension $(80 / 50 \mathrm{mmHg})$, feeble radial pulse, and a blood sugar level of $112 \mathrm{mg} / \mathrm{dL}$. Repeat ECG was suggestive of inferior wall myocardial infarction with ST elevation in lead II, III , AVF and depression in I, AVL, V1, V2, V3 [Fig.2]. 


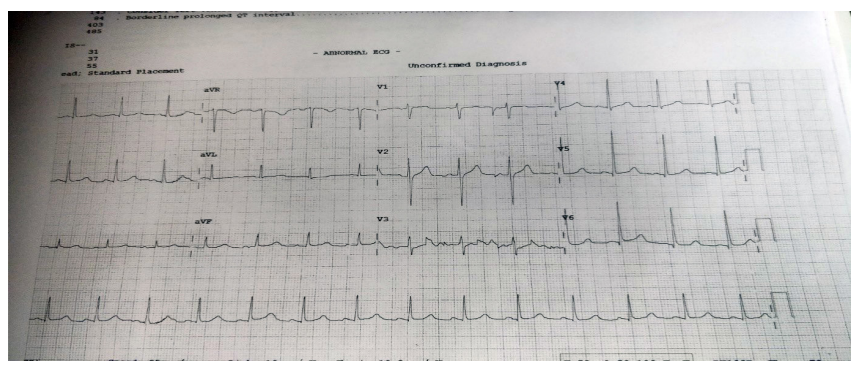

Fig.1: ECG at admission showing normal sinus rhythm.

An immediate cardiac consultation was sought, and patient was given loading of oral ecosprin $325 \mathrm{mg}$, ticagrelor $180 \mathrm{mg}$ and atorvastatin $80 \mathrm{mg}$ and was planned for immediate cardiac catheterization. 20 minutes later, monitor showed normal sinus rhythm. Patient also reported significant improvement. Repeat ECG done revealed normal sinus rhythm [Fig.3] Cardiac enzymes were within normal limits (Trop I $0.04 \mathrm{ng}$ / mL, CK MB 1.3 IU/L). Echocardiography done at the time of event showed no regional wall motion abnormality with ejection fraction of 55\% [Fig.4].

As per decision of cardiologist, patient underwent coronary angiography which revealed normal coronary circulation [Fig.5]. He was subsequently observed in coronary care unit and remained asymptomatic. He was finally discharged after two days with diagnosis of Prinzmetal angina on oral diltiazem.

\section{Discussion}

In 1772, William Heberden, a British physician, aptly described the features of classical angina of effort, which mostly occurs with exertion. This was later attributed to fixed obstructive coronary atherosclerotic disease and associated with dynamic ST segment depression on the electrocardiogram (ECG) during pain. In 1959 Prinzmetal described 32 cases of angina occurring at rest, reporting that the clinical characteristics of these patients differed to those with Heberden's classical angina of effort since: (i) angina did not occur with exertion; (ii) ST segment elevation rather than depression occurred during pain; (iii) angina episodes often

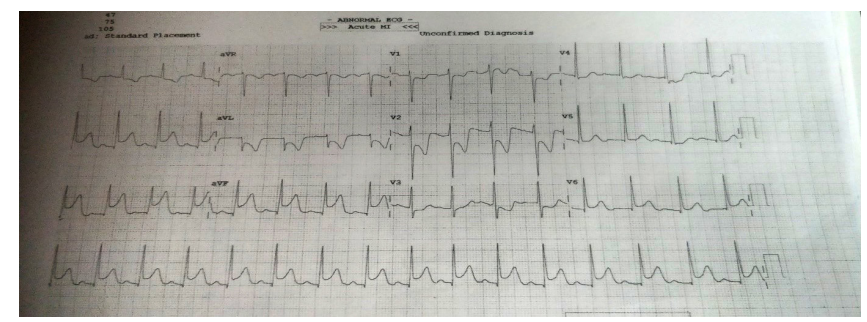

Fig.2: ECG during event showing features of inferior wall myocardial infarction.

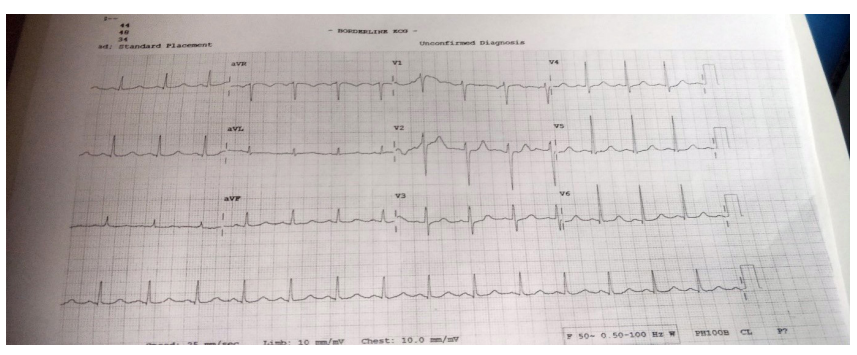

Fig.3: Post-event ECG showing normal sinus rhythm.

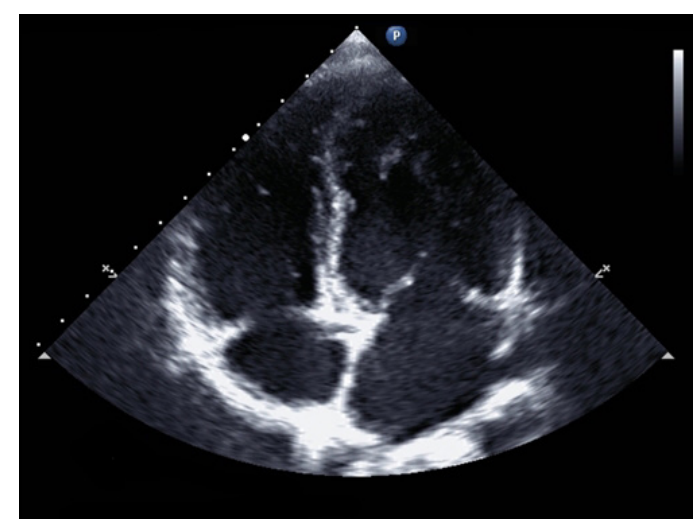

Fig.4: Echocardiography showing normal study.

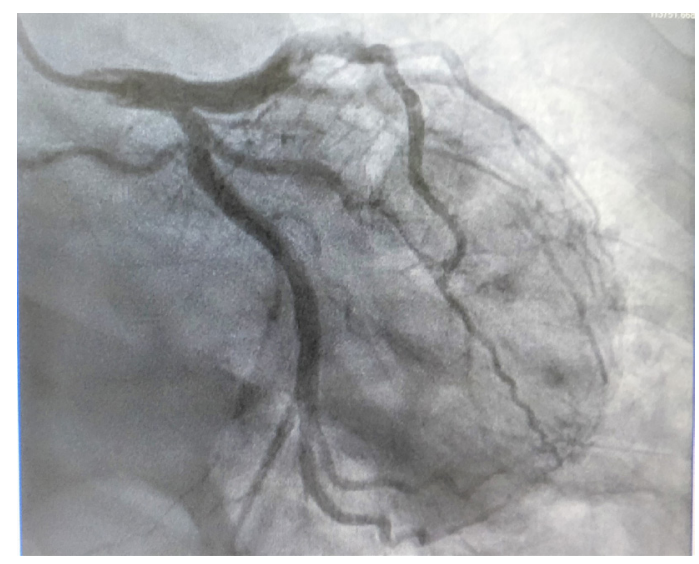

Fig.5: Normal coronary angiography. 
recurred at the same time frequently awaking the patient from sleep; (iv) angina may be associated with arrhythmias or progress on to myocardial infarction [1].

In contrast to patient with unstable angina secondary to coronary atherosclerosis, patients with Prinzmetal angina are generally younger and have fewer coronary risk factors (except smoking). Episode of chest pain usually does not progress from a period of chronic stable angina. Cardiac examination is usually normal in the absence of ischemia. Probable mechanisms responsible for Prinzmetal angina are (i) Enhanced contractility of coronary vascular smooth muscle due to reduced nitric oxide bioavailability caused by a defect in the endothelial nitric oxide synthetase enzyme which leads to endothelial function abnormalities [2]. (ii) Thromboxane A2, a vasoconstrictor released by platelets to aid in clot formation. Lipoprotein(A) interferes with fibrinolysis by competing with plasminogen. The impaired fibrinolysis triggers thrombus formation, which results in coronary vasospasm in Prinzmetal angina [1]. (iii) Increased alpha-adrenergic receptor activity on epicardial coronary arteries leads to coronary vasospasm [3].

Although Prinzmetal's angina has been documented in between $2-10 \%$ of angina patients, it can be overlooked by cardiologists who stop testing protocol after ruling out typical angina. Rarely, an ECG can capture diffuse ST elevations. Patients who develop cardiac chest pain are generally treated as an "acute coronary syndrome", and are generally tested for cardiac enzymes such as creatine kinase isoenzymes or troponin I or T. These may or may not show a degree of positivity, as coronary spasm too can cause myocardial damage or may leave the arteries undamaged. Echocardiography or thallium scintigraphy is often performed. The gold standard diagnostic test is coronary angiography [4].

This awareness is important in Emergency Medicine as coronary vasospasm, if prolonged can cause acute myocardial infarction by itself or by causing intra-luminal thrombus or rupture of minor atherosclerotic plaque. Such narrowing, even less than 50\%, can be dangerous [5]. Prolonged spasm can cause acute coronary syndrome, fatal arrhythmias like ventricular fibrillation, ventricular tachycardia, complete atrio-ventricular block and electromechanical dissociation [6]. Prinzmetal's angina typically responds to nitrates and calcium channel blockers.

\section{Conclusion}

Prinzmetal angina is rare. Extreme caution should be exercised in patient presenting to ED with intermittent symptoms pertaining to systemic poor perfusion. Awareness regarding existence of Prinzmetal angina is important to Emergency physician in deciding disposition of patient in crowded ED.

Acknowledgement: Dr. Rajeev Rathi, Department of Cardiology, Max Super Specialty Hospital, Saket, New Delhi. Contributors: KVD: manuscript writing, patient management; SJ, AP: manuscript editing, patient management; MM: critical inputs into the manuscript. RR: cardiac care inputs into the manuscript. KVD will act as guarantor. All authors approved the final version of this manuscript.

Funding: None; Competing interests: None stated.

\section{References}

1. Prinzmetal M, Rexford K, Reuben R, Wada T, Bor N. Angina pectoris I. A variant form of angina pectoris. The American Journal of Medicine. 1959;27:375-388.

2. Yoo SY, Kim JY. Recent insights into the mechanisms of vasospastic angina. Korean Circulation Journal. 2009;39:505-511.

3. Yasue H, Touyama M, Kato H, Tanaka S, Akiyama F. Prinzmetal's variant form of angina as a manifestation of alpha-adrenergic receptor-mediated coronary artery spasm: Documentation by coronary arteriography. American Heart Journal. 1976;91:148-155.

4. Hung MJ, Cherng WJ. Coronary Vasospastic Angina: Current Understanding and the Role of Inflammation. Acta Cardiologica Sinica. 2013;29:1-10.

5. Takatsu F, Watarai M. Mild stenosis makes prognosis of vasospastic angina worse. Coron Artery Dis. 2011;22:1-5.

6. Nakamura M, Takeshita A, Nose Y. Clinical characteristics associated with myocardial infarction, arrhythmias, and sudden death in patients with vasospasm tic angina. Circulation. 1987;75:1110-1116. 